\title{
Information Sources and Domestic Tourism at Sanyuesan Festival, China
}

\author{
Qin $\mathrm{Xi}^{1}$, Ousanee Sawagvudcharee ${ }^{2}$, John Walsh ${ }^{3}$ \\ ${ }^{1}$ Ph.D., Candidate, Management, School of Management, Shinawatra University, Thailand \\ ${ }^{2} \mathrm{Ph}$. D., Management, School of Management, Shinawatra University, Thailand \\ ${ }^{3} \mathrm{Ph}$. D., International Business, School of Business and Management, RMIT, Vietnam \\ Correspondence: John Walsh, Ph. D., International Business, School of Business and Management, RMIT, \\ Vietnam. E-mail: jcwalsh100@hotmail.com
}

Received: June 20, 2019

doi:10.5539/ibr.v12n8p23
Accepted: July 16, $2019 \quad$ Online Published: July 18, 2019

URL: https://doi.org/10.5539/ibr.v12n8p23

\begin{abstract}
Festival tourism is part of a phenomenon which is rather larger than its tourism component. The relationship between people and the various elements of the festival may be complicated by the changing availability of information sources, including web-based sources, as well as changing relationships towards those sources with respect to access ease and trust. A sample of 400 respondents was achieved via online questionnaire distribution to investigate these issues and to formulate lessons that might inform marketing strategies relating to future iterations of the festival. It was found that no straightforward relationships existed with respect to segmentation of the sample and, therefore, population and that attitudes towards both information sources and the institutions of the festival are undergoing a process of change.
\end{abstract}

Keywords: consumer behaviour, China, festival tourism, information sources, online search

\section{Introduction}

The Sanyuesan or March $3^{\text {rd }}$ Festival is an annual event celebrated by a number of different ethnic minority groups across southern China from the third day of the third lunar month. In addition to providing the means for reproducing social relations at the beginning of Spring, this festival has the ancillary purpose of offering young people opportunities to meet each other in conditions which are considered non-scandalous. Many of the activities practised at the festival offer young women and men the opportunity to show off their prowess and to interact with each other. As China opened itself to the world, festivals such as this were used as opportunities to display the cultural capital of minority ethnic people. In some cases, the participants and activities were adjusted for the sake of tourists, by holding annual festivals on a daily or weekly basis or changing the women's attire to make them more alluring. The minority people (some of them in fact are played by Han Chinese) appear in the guise of the other and their diversity from the norm is emphasised (Yang \& Hu, 2011). However, most Sanyuesan activities have managed to retain some measure of authenticity.

The largest ethnic minority group in China is the Zhuang, a Tai-speaking people related to Thai and Lao people and other groups in Viet Nam and Myanmar. The main home of the Zhuang people is the Guangxi Zhuang Autonomous Region in south eastern China, bordering Viet Nam. The capital of the region is Nanning, where more than 750,000 of the overall 16 million Zhuang people live. Although they are now integrated into mainstream daily life in an urban environment, the Sanyuesan Festival offers an opportunity for people to commemorate their history and celebrate their traditions. This has also become an attraction for people from across China and beyond.

In 2018, the Sanyuesan Festival in Guangxi province attracted 163,000 visitors across the five days of celebration with associate expenditure of 12.6 billion yuan (\$US1.8 billion). This has become, in other words, quite a significant economic event. It has been boosted in this by early support from \& the Chinese Communist Party, who from an early date recognised it as a genuine expression of cultural capital (Kaup, 2000:101). The festival provides a potential regular economic stimulus that would be of great value to Zhuang people.

As China has developed, more of its people have gained the disposable income which betokens entry into the bourgeois classes. Chinese tourism has become familiar in the international context with large numbers of 
tourists now visiting East and Southeast Asian countries and, also, for wealthier Chinese, Europe and North America. However, domestic tourism in China is less well-known. A recent estimate indicated that domestic attractions were visited 2.8 billion times in the first half of 2018 and this was an increase of $11.4 \%$ on the previous year. The value of the market was estimated at US\$359 billion (China Daily, 2018). This is mostly urban to rural tourism or urban to urban tourism, with a sizeable component of 'red tourism' related to the history of the Chinese Community Party $(\mathrm{Li}, 2008)$. However, despite the emergence of many new and often successful tourist sites and activities, it is not clear to what extent traditional activities such as the Sanyuesan Festival actually meets the needs of actual or potential customers. One way of investigating this is through examination of internet searches for the festival and cross-referencing this with activities and satisfaction. Internet usage has risen very rapidly in China and the rise of ecommerce platforms indicates how popular this activity has become. China has more than 730 million internet users and its mobile payment market is 11 times the size of that in the USA (Marinova, 2017).

What, therefore, is the connection between Chinese domestic tourism, ecommerce use and the role of traditional folk festivals in contemporary China? This paper reports on quantitative research conducted to investigate these issues with respect to the 2018 Sanyuesan Festival in Nanning and Guangxi Zhuang Autonomous Region. Particular attention is paid to the issue of information sources and methods of booking.

\section{Literature Review}

\subsection{Heritage Tourism}

Domestic tourism based on the Sanyuesan Festival should properly be considered a form of heritage tourism. Heritage tourism is not strictly defined but based on the idea of " ... tourism related to what we have invented (McCain \& Ray, 2003)." Those people who have a personal connection to the heritage may be called 'legacy tourists.' Zhuang people travelling from other parts of China to where they might have migrated and returning to attend the festival would be considered legacy tourists. Contemporary approaches to philosophy, since at the least the formulation of post-modernism, requires the interrogation of authenticity as a means of approaching the genuine value of an experience. To some extent, a sense of authenticity may be managed from some people (Chhabra, Healy \& Sills, 2003). It has been observed that the "desire for authenticity now occupies a central position in contemporary culture (Fine, 2003)." The perception of authenticity has been shown to have direct impacts on the satisfaction and experience of a site ( $\mathrm{Lu}$, Chi \& $\mathrm{Lu}, 2015)$. However, it is not always a positive dimension of a site or activity and there may be many stakeholders who will be unhappy with expressions of negative authenticity (Zhou et al., 2018). There is, certainly, sufficient evidence of unfortunate historical events in Chinese memories to create a large amount of negative authenticity. However, there is less information available about the consumer behaviour of Chinese tourists with respect to Festival tourism. 'Festival tourism' has been defined as involving socially sustaining devices that have meanings that go far beyond tourism, although that can be a significant component part (Quinn, 2006). It would be expected that, especially in connection with a domestic festival, potential tourists would have some knowledge of the social capital embedded within the events and to have a broader and more complex relationship with them than for other people. Consequently, it will be relevant to explore the implications of this for consumer behaviour in this context.

\subsection{Information Sources}

As communications increasingly take place online or via computer-moderated systems, it is not surprising that tourists too search for information about potential resort destinations in the same way. In doing so, the exact nature of the medium of communication changes and evolves and the nature of trust with different media also evolves (Munor \& Jacobsen, 2013). Tourists generally respond to trust issues by obtaining information from a number of different web-based sources and according different levels of trust to them depending on personal and shared experiences (No \& Kim, 2015). The research suggests that tourists will use information sources as a means of selecting different options (Andereck \& Caldwell, 1994). The willingness of people to search for this information using their own time and resources indicates one of the more important ways that e-commerce has reinvigorated business activities (Werthner \& Ricci, 2004). Expedia, for example, is a travel and reservations company based on the willingness of users to submit their opinions as content for the website. Now it is responsible for bookings for 325 million room nights in 2018 and had annual revenue of US\$11.2 billion (Expedia, 2019). There are various other companies that have also achieved high levels of success in an industry estimated to be worth US $\$ 1.6$ trillion annually.

There are numerous examples of the ways in which trust varies in terms of both time and space (Freitag \& Bauer, 2013). Indeed, the work of Hofstede (e.g. 1980) and various followers have demonstrated extensively variations 
across different societies. Although there may be differences in levels of trust which may be affected by such structural issues as means of payment and guaranteed receipt of goods, basic consumer behaviour principles are observed around the world (Teo \& Liu, 2007). Nevertheless, as Chinese society changes, the levels of trust in institutions varies $(\mathrm{Li}, 2004)$ and may indicate the uneven nature of development in the country (Yang \& Tang, 2010) and the presence of corruption, which has been made evident through various high-profile campaigns (Zhu, Lu \& Shi, 2013).

\section{Methodology}

There has been in recent years a definite movement from paper-based quantitative data collection to internet-based data collection. In China, the website which has come to be pre-eminent in such data collection is Wenjuan. Founded in Shanghai in 2004, Wenjuan offers various data collection, distribution and analytical services with a free online survey platform and an innovative management technology platform (Crunchbase, 2018). This website was used as the principal means of data collection. After a process of examining the secondary literature and consultation, a customised questionnaire was produced to be distributed to people seeking holiday-based information via digital promotions. The ability to target the respondents in this way was considered to be one of the more attractive features of using this method. Participants are first contacted by mobile telephone and, if they wish to participate, scan a QR code which takes their device directly to the relevant section of the Wenjuan website.

Owing to the nature of internet data collection, questions tend to be simple, closed multiple choice varieties, although there is some scope for more subtle approaches. Pilot tests are best conducted with friends and acquaintances beforehand since modifying an existing questionnaire on the website is problematic.

The questionnaire is written in Chinese and respondents answered the 19 close-ended questions in that language. The questions were divided into demographic characteristics (i.e. gender, age, monthly income and occupation) and questions based on the seven elements (7Ps) of marketing: place; people; price; promotion; product; process and physical evidence.

A total of 741 respondents in Nanning were contacted by mobile telephone and agreed to complete the questionnaire, which the website recorded taking between 1.1 to 61.4 minutes. According to the Yamane equation, 400 responses would be sufficient to represent the population of the estimated size at a confidence level of $95 \%$. Consequently, a purposeful decision was taken to balance the sample with respect to the population (e.g. a surplus of students was present in the original sample) and 341 samples were randomly selected for exclusion from the identified categories. This process also enabled the exclusion of responses which appeared to offer incomplete or inconsistent responses. It is believed that all remaining responses were submitted in good faith by humans (i.e. not bots). Even so, the sample was not balanced in terms of some demographic categories. For example, $68.8 \%$ of respondents were female and only $30.2 \%$ were male.

Data collection required only three days since the online data collection site averaged 240 completed responses per day. After being vetted and checked, responses were entered into the statistical programme SPSS for analysis.

\section{Findings}

The Guangxi Tourism Development Committee indicated that there were 623,000 internet searches for information on tourism in the province during the period January $1^{\text {st }}$-March $31^{\text {st }}, 2018$. Of these, the Chinese language sites Weibo and Wechat were the most commonly used.

Table 1. Channels for Internet Information Searches, January-March, 2018; source: Guangxi Tourism Development Committee

\begin{tabular}{lll}
\hline Channel & No. of Searches & \%age \\
\hline Weibo & 209,000 & 33.5 \\
Wechat & 136,000 & 21.9 \\
Other website & 122,000 & 19.5 \\
News sites & 39,000 & 6.3 \\
Clients & 85,000 & 13.7 \\
Forums & 28,000 & 4.5 \\
Government affairs & 14,000 & 2.2 \\
Blogs & 9,000 & 1.5 \\
Magazines & 5,000 & 0.9 \\
Overseas media & 400 & $<0.1$ \\
Video media & 2,000 & 0.3 \\
\hline
\end{tabular}

The most commonly used sites are those where the content is controlled by the users, i.e. they result from 
conversations and interactions with online friends and companions. The sites where the content is determined by website controllers or editors (e.g. news sites or magazines) are much less likely to be consulted. It is possible to argue that this is at least partly the result of the levels of trust that Chinese people have with respect to different types of information source. Only $1.1 \%$ of information searches overall were considered to be involved with sensitive information, so it seems unlikely that many of the respondents here were using specific sources to avoid drawing attention to themselves.

When respondents were asked more specifically about obtaining information about Sanyuesan Festival, it was found that Wechat was again the most commonly used source, followed by active promotions.

Table 2. Internet searches for Information about Sanyuesan Festival, 2018; original research $(\mathrm{n}=400)$

\begin{tabular}{llll}
\hline Channel & \%age & Channel & \%age \\
\hline Wechat & 62.3 & Activity promotions & 44.8 \\
Other media & 32.3 & Radio & 26.5 \\
Official website & 28.0 & Weibo & 27.5 \\
Magazines & 24.5 & Outdoor advertisements & 17.0 \\
Television and movie advertisements & 14.3 & & \\
\hline
\end{tabular}

This table indicates that an interesting combination of push and pull media sources has been consulted by respondents. It suggests that it is really worthwhile for promoters to continue to use the traditional media of radio, television and magazine advertisements but these should be part of a mixed communications strategy with more direct and interactive approaches. These are relatively new ideas for Chinese public sector agencies.

When further asked about whether respondents were aware of the official Festival logo as used on websites, Weibo and Wechat, $47.5 \%$ said that they had, while a further $35.8 \%$ were not sure and $16.8 \%$ did not know the logo. This is quite a positive result but it does indicate that there is scope for further improvement. This is reinforced by the fact that when asked for additional comments about online information relating to the Festival, $50.0 \%$ thought that there was inadequate information about accommodation and food and beverages in the site, $35.5 \%$ thought there was a lack of attractive online experiences for young people, 31,8\% observed that official websites and presence on Wechat and Weibo was outdated, 30.8\% noted imperfect cooperation with third party organizations and $27.5 \%$ talked about the unsupervised online marketing of derivative products $(n=400$, source: original research).

Attempts were made to try to determine whether respondents would be more influenced by profile, behavioural or psychographic variables, following the argument of Tkaczynski, Rundle-Thiele \& Beaumont (2009). This was to explore the different ways in which segments might be made up with respect to different events and resorts and whether these will change in various ways. The profile variables included demographic, socio-economic and geographic variables. The behavioural variables include benefit sought, purchase occasion purchase behaviour, usage, perceptions and beliefs. Finally, the psychographic variables related to lifestyle and personality issues. These variables were cross-tabulated with the respondent's brand awareness to determine whether a statistically significant result was obtained. The results of this are shown in the following table:

Table 3. Significance of Profile, Behavioural and Psychographic Variables; source: Original Research

\begin{tabular}{llll}
\hline Variable & N & Sig. & Category \\
\hline Monthly income & 400 & $0.021^{* 1}$ & Profile \\
Venue & 400 & $0.013^{*}$ & Behavioural \\
Magazine & 400 & $0.006^{* *}$ & \\
Official website & 400 & $0.010^{* *}$ & \\
Whom go with & 400 & $0.000^{* *}$ & \\
Booking access & 400 & $0.033^{*}$ & \\
Payment method & 400 & $0.008^{* *}$ & \\
Coupon access & 400 & $0.000^{* *}$ & \\
Folk singing & 400 & $0.000^{* *}$ & Psychographic \\
Folk sports & 400 & $0.035^{*}$ & \\
Culture activities & 400 & $0.003^{*}$ & \\
Not participants & 400 & $0.000^{* *}$ & \\
Other souvenirs & 400 & $0.045^{*}$ & \\
Coupon contents & 400 & $0.037^{*}$ & \\
Inadequate service of official website & 400 & $0.024^{*}$ & \\
\hline
\end{tabular}

${ }^{1}$ In this paper, the convention is followed that a single asterisk denotes a distribution that is statistically significant at the 0.05 level and double asterisks are used for a result that is statistically significant at the 0.01 level. 
Inadequate service of 020 promotion $400 \quad 0.001 * *$

It is evident from these results that there are numerous statistically significant distributions obtained here, which suggests that the analysis has identified a meaningful way of understanding the overall results. Further analysis indicates that the results vary quite considerably. For example, higher levels of engagement with particular aspects of the festival are associated with higher levels of knowledge of the brand. Meanwhile, the source of information about the event also was associated with differing levels of brand awareness. It appears that, at the very least, it would be possible to identify different segments of consumers with the overall sample with regard to their level of engagement and knowledge of the festival. It would also be possible to identify some useful means by which it would be possible to communicate with the different segments.

Table 4. Distribution of Preferred Destinations Cross-tabulated by Demographic Characteristics; source: Original Research

\begin{tabular}{llllll}
\hline Activity & Gender & Age & Salary & Position & N \\
\hline Wuming & 0.053 & 0.144 & 0.591 & 0.802 & 400 \\
Chongzuo & 0.211 & $0.000^{* *}$ & $0.000^{* *}$ & $0.000^{* *}$ & 400 \\
Nanning & $0.009^{*}$ & $0.001^{* *}$ & 0.096 & 0.721 & 400 \\
Liuzhou & 0.232 & 0.313 & 0.719 & 0.947 & 400 \\
Laibin & $0.031^{*}$ & 0.406 & 0.767 & 0.550 & 400 \\
Hechi & 0.516 & 0.648 & 0.057 & 0.235 & 400 \\
Guilin & 0.329 & 0.936 & 0.259 & 0.330 & 400 \\
Others & 0.409 & $0.008^{* *}$ & $0.020^{*}$ & 0.126 & 400 \\
\hline
\end{tabular}

It is evident that the demographic characteristics have been influential in providing statistically significant distribution only in the cases of Chongzuo and Nanning, with some significant results also noticeable for the 'other' category. In the case of Chongzuo, people aged 18-24 were much more likely to attend (28.1\%) than people in other categories, while people without a salary (44.950 were much more likely to attend than others and, perhaps in a related way, students $(47.1 \%)$ are also much more likely to have attended. In the case of Nanning, women (54.8\%) were much more likely to have attended than men, while older people (above 50) were much more likely to attend $(74.5 \%)$ than others.

Table 5. Overall Attendance at Different Events; source: Original Research

\begin{tabular}{lll}
\hline $\mathbf{N = 4 0 0}$ & Yes & No \\
\hline Wuming & 8.5 & 91.5 \\
Chongzuo & 15.0 & 85.0 \\
Nanning & 50.8 & 49.3 \\
Liuzhou & 6.5 & 93.5 \\
Laibin & 1.3 & 98.8 \\
Hechi & 3.0 & 97.0 \\
Guilin & 6.3 & 93.8 \\
Others & 27.8 & 72.3 \\
\hline
\end{tabular}

Again, it is shown that attendance depended to a considerable extent upon location, as might be expected. Convenience in transportation is known to be an influential factor in determining tourist behaviour.

Table 6. Distribution of Information sources Consulted Cross-Tabulated by Demographic Variables; source: Original Research

\begin{tabular}{llllll}
\hline Sig. & Gender & Age & Salary & Vocation & N \\
\hline Newspaper/magazine & 0.234 & 0.427 & $0.003^{* *}$ & 0.180 & 400 \\
Government website & 0.485 & $0.024^{*}$ & 0.057 & 0.217 & 400 \\
Weibo & $0.012^{*}$ & $0.001^{* *}$ & 0.117 & 0.470 & 400 \\
Wechat & $0.011^{*}$ & 0.070 & 0.579 & 0.607 & 400 \\
Billboard & 0.185 & 0.616 & 0.204 & $0.013^{*}$ & 400 \\
Advertising & $0.004^{* *}$ & $0.032^{*}$ & $0.017^{*}$ & $0.008^{* *}$ & 400 \\
TV & 0.313 & 0.996 & 0.486 & 0.061 & 400 \\
Radio & 0.135 & 0.403 & 0.079 & 0.211 & 400 \\
Other media & 0.242 & $0.001^{* *}$ & $0.000^{* *}$ & $0.011^{*}$ & 400 \\
\hline
\end{tabular}

In terms of the demographic characteristics and the influence on information sources consulted, it is evident from table 6 above that a number of distributions are significantly affected by them. This is most obviously so in the case of advertising, although gender, age, salary and vocation all register some significant distributions. This suggests that there is no single pattern that can explain the variations observed. Instead, different groups of people join together in different segments for a variety of different reasons. 
Table 7. Overall Figures for Consultation of Information Sources; source: Original Research

\begin{tabular}{cc}
\hline Information source & \%oage saying 'yes' \\
\hline Newspaper/magazine & 24.5 \\
Government website & 28.0 \\
Weibo & 27.5 \\
Wechat & 62.3 \\
Billboard & 17.0 \\
Advertising & 44.8 \\
TV & 14.3 \\
Radio & 26.5 \\
Other media & 32.3 \\
\hline
\end{tabular}

It is clear that the most important source of information was Wechat (62.3\% of respondents consulted it), followed by advertising (44.8\%) and other media (32.3\%). Further analysis indicated that cross-tabulation by age, salary and vocation showed three statistically significant distributions each. In terms of newspapers and magazines, it was significantly more likely that mid-range salary people wold consult these compared to lower or higher ends of the pay scale. For government website, older respondents (40+) were more likely to consult this source than younger age groups. In the case of Weibo, women (31.2\%) were more likely to use it than men $(19.0 \%)$ and younger people (39.0\%) were much more likely to consult it than those aged 40-50 (15.6\%) and $50+(13.7 \%)$. For Wechat, women $(66.3 \%)$ were more likely to consult it than men $(52.9 \%)$. In the case of billboards, these were much more likely to be consulted by government workers (41.7\%) and homemakers (42.9\%) than for all other categories of occupation. For advertising, every demographic variable produced a statistically significant result. Women $(49.5 \%)$ were more likely to use it than men $(33.9 \%)$, while younger people (e.g. 18-24, 55.8\%) were much more likely to use it than older groups, for example 40-50 (43.8\%) and $50+(31.4 \%)$. Advertising was much more likely to be used by people without a salary $(60.3 \%)$ than by people in other salary categories and, finally, government officers (54.2\%), company employees $(52.3 \%)$ and students $(60.0 \%)$ and homemakers $(57.1 \%)$ were much more likely to consult it than respondents in other vocational categories. In the case of both television and radio, there were no statistically significant distributions for any of the variables, which rather suggests that these media have now fully penetrated every sector of the population. Finally, for other media, these were much more likely to be used by young people and by people with salaries in the range of 3,001-5,000 and 8,001-12,000 yuan than by other respondents. They were also particularly popular among government officers (50.0\%), the self-employed (44.4\%) and students (48.6\%) than for other respondents.

Turning to the issue of favourite activities or shows at the festival, the overall results showed:

Table 8. Overall Attendance at Different Activities; source: Original Research

\begin{tabular}{cc}
\hline Activity & \&age saying 'yes' \\
\hline Folk music & 49.3 \\
Folk competitions & 36.8 \\
Tourism & 44.8 \\
Folk art & 57.0 \\
Folk craft show & 33.5 \\
Food festival & 45.3 \\
Others & 11.0 \\
Did not attend & 8.5 \\
$\mathrm{~N}$ & 400 \\
\hline
\end{tabular}

It is evident that the folk art activity was the most popular (57.0\%), followed by the folk music (47.3\%), food festival (45.3\%) and tourism (44.8\%). There was a reasonable amount of popularity for the folk competitions (36.8\%) and the folk craft show (33.5\%). It is reasonable to assume, therefore, that different groups of people in the sample are interested in different types of activities and it is necessary to adopt a mixed approach to marketing the festival as a result.

\section{Discussion}

The findings indicate that Chinese domestic tourists do use a variety of different information sources in deciding which type of activities they wish to visit. I the context of a festival at which a number of different activities are available, it is apparent that there is no single way of understanding how people will behave or how they will use information sources. This rather suggests that consumer behaviour is evolving in China as new opportunities emerge and relationships with social and political institutions change. Although this is not in itself surprising, it does indicate that attempting to enforce a reductionist understanding on the Chinese market would be a mistake. 
This suggests that a sophisticated information provision strategy would be necessary. This finding is consistent with the work of Tkaczynski et al. (2009).

In terms of the relationship between Chinese people and the sustaining symbols of Chinese society, it also seems to be the case that there is no simple relationship to be found, at least from this research project. Different people prefer different types of activities for a variety of different reasons which are not easily predicted. It is possible that evolution and maturity of information usage will, in due course, enable this to be a more understandable area.

\section{Conclusion}

This paper has reported on quantitative research relating to domestic tourism consumer behaviour relating to Sanyuesan Festival in Guangxi province of China. A total of 400 questionnaires were collected and analysed and the results showed a complicated series of results that are not immediately amenable to simplistic forms of interpretation. It is likely that these results indicate a process of evolution is taking place with respect to the consumption of information in Chinese society and its influence on consumer behaviour is similarly in a process of change. Further research is required to determine the extent to which these issues will become clearer in the future.

Quantitative research is subject to a number of limitations with respect to sample selection and achievement. These problems become more obvious when respondents self-select, as is the case here. Consequently, further research is required to confirm or disconfirm these findings.

\section{References}

Andreck, K. L., \& Linda, L. C. (1994). The influence of tourists' characteristics on ratings of information sources for an attraction. Journal of Travel and Tourism Marketing, 2(2-3), 171-190. https://doi.org/10.1300/J073v02n02_11

Chhabra, D., Robert, H., \& Erin, S. (2003). Staged authenticity and heritage tourism. Annals of Tourism Research, 30(3), 702-719. https://doi.org/10.1016/S0160-7383(03)00044-6

China Daily (2018). China sees rise in number of domestic tourists (July $24^{\text {th }}$ ), available at: http://www.chinadaily.com.cn/a/201808/24/WS5b7f6198a310add14f3878a1.html

Crunchbase (2018). Wenjuan.com, available at: www.crunchbase.com/organization/wenjuan.com

Expedia (2019). Expedia group overview, available at: www.expediagroup.com/about

Fine, G. A. (2003). Crafting authenticity: The validation of identity in self-taught art. Theory and Society, 32(2), 153-180. https://doi.org/10.1023/A:1023943503531

Freitag, M., \& Paul, C. B. (2013). Testing for measurement equivalence in surveys: Dimensions of social trust across cultural contexts. Public Opinion Quarterly, 77(S1), 24-44. https://doi.org/10.1093/poq/nfs064

Hofstede, G. (1980). Culture's consequences: International differences in work-related values, Beverly Hills CA: Sage Publications.

Kaup, K. P. (2000). Creating the Zhuang: Ethnic policies in China, Boulder, CO and London: Lynne Rienner Publishers.

Li, L. J. (2004). Political trust in rural China. Modern China, 30(2), 228-258. https://doi.org/10.1177/0097700403261824

Li, Y. P. (2008). Red tourism in China. Journal of China Tourism, 4(2), 156-171. https://doi.org/10.1177/0097700403261824

Lu, L., Christina, G. C., \& Yi, L. (2015). Authenticity, involvement and image: Evaluating tourist experiences at historic districts. Tourism Management, 50, 59-70. https://doi.org/10.1016/j.tourman.2015.01.026

Marinova, P. (2017). China ecommerce: This is only the beginning for China's ecommerce explosive growth. Fortune (December $5^{\text {th }}$ ), available at: fortune.com/2017/12/04/china-ecommerce/growth.

McCain, G., \& Nina, M. R. (2003). Legacy tourism: The search for personal meaning in heritage travel. Tourism Management, 24(6), 713-717. https://doi.org/10.1016/S0261-5177(03)00048-7

Munor, A. M., \& Jens Kr. S. J. (2013). Trust and involvement in tourism social media and web-based travel information sources. Scandinavian Journal of Hospitality and Tourism, 13(1), 1-19.

https://doi.org/10.1080/15022250.2013.764511 
No, E. J., \& Jin, K. K. (50). Comparing the attributes of online tourism information sources. Computers in Human Behavior, 50, 564-575. https://doi.org/10.1016/j.chb.2015.02.063

Quinn, B. (2006). Problematising 'festival tourism:' Arts festivals and sustainable development in Ireland. Journal of Sustainable Tourism, 14(3), 288-306. https://doi.org/10.1080/09669580608669060

Teo, Thompson, S. H., \& Jing, L. (2007). Consumer trust in e-commerce in the United States, Singapore and China. Omega, 35(1), 22-38. https://doi.org/10.1016/j.omega.2005.02.001

Tkaczynski, A., Sharyn, R. R. T., \& Narelle, B. (2009). Segmentation: A tourism stakeholder view. Tourism Management, 30(2), 169-175. https://doi.org/10.1016/j.tourman.2008.05.010

Werthner, H., \& Francesco, R. (2004). "E-commerce and tourism. Communications of the ACM, 47(12), 101-105. https://doi.org/10.1145/1035134.1035141

Yang, L., \& Hu, Z. Y. (2011). Ethnic tourism and cultural representation. Annals of Tourism Research, 38(2), 561-585. https://doi.org/10.1016/j.annals.2010.10.009

Yang, Q., \& Tang, W. F. (2010). Exploring the sources of institutional trust in China: Culture, mobilization, or performance? Asian Politics and Policy, 2(3), 415-436. https://doi.org/10.1111/j.1943-0787.2010.01201.x

Zhou, Q. L., Jie, Z., Zhang, H. L., \& Xiang, L. (2018). Is all authenticity accepted by tourists and residents? The concept, dimensions and formation mechanism of negative authenticity. Tourism Management, 67, 59-70. https://doi.org/10.1016/j.tourman.2017.12.024

Zhu, J. N., Jie, L., \& Shi, T. J. (2013). When grapevine news meets mass media: Different information sources and popular perceptions of government corruption in mainland China. Comparative Political Studies, 46(8), 920-946. https://doi.org/10.1177/0010414012463886

\section{Copyrights}

Copyright for this article is retained by the author(s), with first publication rights granted to the journal.

This is an open-access article distributed under the terms and conditions of the Creative Commons Attribution license (http://creativecommons.org/licenses/by/4.0/). 